\title{
High Spyl expression predicts poor prognosis in colorectal cancer
}

This article was published in the following Dove Press journal: Cancer Management and Research

\section{Qin Jin ${ }^{1, *}$ \\ Gang Liu',* \\ Luri Bao ${ }^{3, *}$ \\ Yuzhen $\mathrm{Ma}^{4}$ \\ Huidong $\mathrm{Qi}^{5}$ \\ Zhizhong Yun ${ }^{4}$ \\ Yanfeng Dai ${ }^{2}$ \\ Shu Zhang'}

'Department of Pathology, Affiliated Hospital of Nantong University, Nantong, People's Republic of China; ${ }^{2}$ State Key Laboratory of Reproductive Regulation and Breeding of Grassland Livestock, College of Life Science, Inner Mongolia University, Hohhot, People's Republic of China; ${ }^{3}$ Department of Pathology, Inner Mongolia Medical University, Hohhot, People's Republic of China; ${ }^{4}$ Centre of Reproductive Medicine, Inner Mongolia Hospital, Hohhot, People's Republic of China; ${ }^{5}$ Medical School of Nantong University, Nantong, People's Republic of China

*These authors contributed equally to this work

Correspondence: Gang Liu State Key Laboratory of Reproductive Regulation and Breeding of Grassland Livestock, College of Life Science, Inner Mongolia University, 235 West Univ. Road, Hohhot, Inner Mongolia 01002I, People's Republic of China

Tel +86 47I 4992944

Email liugang@life.imu.edu.cn

Shu Zhang

Department of Pathology, Affiliated Hospital of Nantong University, 20 Xisi

Road, Nantong 22600I, Jiangsu, People's Republic of China

Tel +865138505 2222)

Email tzyfzs@163.com
Background: Spy1 (SPDYA) is a new discovered cell cycle protein capable of promoting cell proliferation dependent on cyclin-dependent kinase-2 activation. However, to the best of our knowledge, the expression of Spy1 in colorectal cancer (CRC) tissues remains virtually unknown. Materials and methods: In this retrospective study, we investigated the mRNA and protein expression levels of Spy1 in CRC tissues and corresponding non-cancerous tissues with the analyses of quantitative real-time polymerase chain reaction, western blotting, and immunohistochemistry. In our research, the prognostic significances of Spy 1 expression were further explored by univariate and multivariate survival analyses of 203 patients who were followed up. Results: The results demonstrated that the levels of Spyl mRNA were significantly higher in CRC tissues compared with corresponding non-cancerous tissues $(p=0.0002)$. The results of immunohistochemistry demonstrated that the expressions of Spy1 were significantly associated with clinicopathological parameters, including $\mathrm{T}$ stage $\left(\chi^{2}=7.126, p=0.028\right)$ and TNM stage $\left(\chi^{2}=9.461, p=0.009\right)$. Kaplan-Meier analysis results indicated that high Spy1 expression $(\mathrm{HR}=2.573, p<0.001)$ and TNM stage $(\mathrm{HR}=1.494, p=0.011)$ were independent factors to predict poor prognosis for patients with CRC.

Conclusion: We concluded that high Spy1 expression is significantly associated with unfavorable prognosis in CRC and could serve as a potential prognostic marker in clinical diagnosis of CRC.

Keywords: Spy1, colorectal cancer, prognostic marker, clinical diagnosis

\section{Introduction}

Colorectal cancer (CRC) is the third most common cancer worldwide, and is also associated with the second highest malignancy mortality worldwide. In 2014, there were projected to be 136,830 individuals newly diagnosed with $\mathrm{CRC}$ and 50,310 CRC deaths in the United States, with over 2.4 million new cases expected to be diagnosed worldwide by $2035 .^{1,2}$ The incidence of CRC is increasing each year, with decreasing age of CRC patients. Therefore, CRC has become a major public health issue.

The fecal occult blood test $(\mathrm{FOBT})^{3}$ and serum diagnostic biomarkers such as carcinoembryonic antigen ${ }^{4}$ and carbohydrate antigen $19-9^{5}$ are used for CRC diagnosis in clinics, but the accuracies of the FOBT and these biomarkers remain unsatisfactory and require improvement. ${ }^{6}$ Alternatively, colonoscopy could significantly improve the diagnosis of CRC. ${ }^{7}$ However, this diagnostic method has shortcomings, such as cost, risk, and inconvenience. ${ }^{8} \mathrm{CT}$ colonography is highly sensitive for CRC detections in clinical, but there is still some limitations such as heterogeneous sensitivity. ${ }^{9}$ Therefore, it is vital to discover new CRC biomarkers with high specificity and sensitivity. 
Cell cycle progression is regulated by sequential activation and inactivation of a series of cyclin-dependent kinases (CDKs). ${ }^{10}$ Spy1 (speedy/RINGO cell cycle regulator family member A; also known as SPDYA) is a member of the Speedy/ Ringo families of cell cycle regulators, which control cell proliferation and survival through the atypical activations of CDKs. ${ }^{11}$ The expression of Spy1 enhances CDK2-dependent $\mathrm{p} 27^{\mathrm{kip} 1}$ degradation during late $\mathrm{G} 1$ phase and throughout $\mathrm{S}$ phase by directly promoting $\mathrm{p} 27$ degradation. ${ }^{12}$ Furthermore, Spy 1 has been shown to override DNA damage response, ${ }^{13}$ functions to inhibit DNA damage-induced apoptosis, and promote mammalian cell survival in response to a number of genotoxic agents, including hydroxyurea, cisplatin, and camptothecin. ${ }^{14}$ Spy 1 expression has been associated with breast cancer, ${ }^{15,16}$ ovarian cancer, ${ }^{17}$ hepatocellular carcinoma, ${ }^{18}$ and multiple myeloma. ${ }^{19}$ However, to the best of our knowledge, the expression of Spy 1 in CRC remains virtually unknown. Therefore, in the present study, we compared the expression of Spy1 protein in CRC tissues and adjacent tissues (as corresponding non-cancerous tissues) using quantitative real-time polymerase chain reaction (qRT-PCR), immunohistochemistry, and western blot analysis. We also investigated its associations with clinical and pathologic factors, as well as the prognostic implications.

\section{Materials and methods}

\section{Patients}

In total, 40 pairs of fresh CRC tissues and adjacent tissues were collected from the Department of Pathology, Affiliated Hospital of Nantong University. Simultaneously, a total of 203 paraffin-embedded CRC tissues and 203 matched adjacent tissues were collected from the Department of Pathology, Affiliated Hospital of Nantong University between January 2009 and June 2011. Diagnoses of CRC were validated by two independent pathologists in the department, according to the International Union Against Cancer and the TNM Classification of Malignant Tumors 7 th edition. None of the included patients received radiotherapy or chemotherapy before surgery. Each patient signed written informed consent for this present study. All cases had corresponding clinical data and follow-up records. The follow-up rate was $100 \%$. The study protocol was approved by the Ethics Committee of the Affiliated Hospital of Nantong University, and all experiments were performed in accordance with approved guidelines of the Affiliated Hospital of Nantong University.

\section{qRT-PCR analyses}

In total, 30 pairs of the collected fresh CRC tissues and adjacent tissues were used for qRT-PCR analysis.
Total RNA was extracted from tissues with Trizol ${ }^{\mathrm{TM}}$ (79306, Gibco, Shanghai, People's Republic of China), and cDNA was synthesized using commercial kits (Prime Script $^{\mathrm{TM}}$ RT reagent Kit with gDNA Eraser, RR047A; TaKaRa, Beijing, People's Republic of China). Amplifications were performed in an ABI Verti 96 well thermal cycler or a Thermo Pikoreal using commercial kits (Premix Taq ${ }^{\text {TM}}$; TaKaRa) and specific synthesized primers. The ubiquitously expressed $\beta$-actin gene was used as an internal control. The integrity of all the DNA fragments amplified by PCRs was confirmed by sequencing. All experiments were performed in triplicate.

The primers for $S p y 1$ were as follows: forward primer 5'-ATT GGG AAA CCA AAA TGA GGC-3' and reverse primer 5'-TCC TGG TAT GCT CAC TTA TAG-3'. $\beta$-actin was used as an internal control, and the primers for $\beta$-actin were as follows: forward primer 5'-TAA TCT TCG CCT TAA TAC TT-3' and reverse primer 5'-AGC CTT CAT ACA TCT CAA-3'. The relative Spy 1 mRNA expression was calculated using the $2^{-\Delta \Delta \mathrm{Ct}}$ method.

\section{Antibodies and western blotting}

Quantified protein lysates from 40 pairs of fresh CRC tissues and adjacent tissues were measured with a Protein BCA assay kit (163-2086; Bio-Rad Laboratories Inc., Hercules, CA, USA) according to manufacturer's instructions. The proteins in lysates were resolved on SDS-PAGE gels (P1200; Solarbio, Beijing, People's Republic of China), transferred onto polyvinylidene fluoride membranes (IPVH00010; EMD Millipore, Billerica, MA, USA), and immunoblotted with anti-human antibodies to GAPDH (ab8245; Abcam, Shanghai, People's Republic of China) and Spy1 (ab153965; Abcam). The blots were visualized with enhanced chemiluminescence (Amersham Biosciences, Shanghai, People's Republic of China) after exposure to X-ray films. GAPDH was stained as a loading control.

\section{Immunohistochemistry analysis}

A total of 203 CRC and adjacent tissue paraffin sections were deparaffinized with xylene and rehydrated in graded ethanol (100-95-85-75\%), and then washed with phosphate-buffered saline solution (PBS, $0.01 \mathrm{M}, \mathrm{pH} 7.0$ ). Antigen retrieval was achieved by boiling under pressure in citrate buffer $(0.01 \mathrm{M}$, pH 6.0). Non-specific binding was blocked through incubation with 5\% goat blocking serum (SL039; Solarbio) in PBS for $30 \mathrm{~min}$ at $37^{\circ} \mathrm{C}$. All paraffin sections were incubated with rabbit anti-Spy1 antibody (1:300, ab153965; Abcam) and subsequently with goat anti-rabbit HRP secondary antibody (ZDR-5306; ZSGB-BIO, Beijing, People's Republic of China). For a color reaction, sections were incubated with the 
DAB substrate chromogen solution (DA1010; Solarbio) for 8 minutes. Subsequently, sections were counterstained with hematoxylin.

Immunostained sections were scored by two independent pathologists under blinded experimental conditions according to intensity and percentage of Spy1-positive cells under light microscope (Axio imager A2; Zeiss, Shanghai, People's Republic of China). The intensity of Spy1-positive cells was scored as follows: 0 ( $0 \%$, negative), 1 ( $1 \%-33 \%$, poor), 2 (34\%-66\%, moderate), and 3 ( $\geq 67 \%$, strong). ${ }^{20}$ The multiplication of the intensity and percentage scores led to the final Spy1 staining score and was defined as follows: staining score less than 3 was considered as low expression, while staining score of 4 or more was considered as high expression.

\section{Comparison of Spyl genes expression level in different cancers}

The GEPIA (http://gepia.cancer-pku.cn/index.html) is a newly developed interactive web server for analyzing the RNA sequencing expression data of 9,736 tumors and 8,587 normal samples from the TCGA and the GTE projects using a standard processing pipeline. ${ }^{21}$ It provides customizable functions such as tumor and normal differential expression analysis, and we could demonstrate the $S p y 1$ gene expression levels in different cancers such as adrenocortical carcinoma (ACC), kidney renal clear cell carcinoma (KIRC) and colon adenocarcinoma (COAD).

\section{Statistical analysis}

The expression levels of Spy 1 mRNA in fresh CRC tissues and adjacent tissues were calculated by the Wilcoxon signedrank nonparametric test. We used Pearson's $\chi^{2}$ to examine the correlations between Spyl protein expression and clinicopathological parameters. Kaplan-Meier and log-rank test were performed to calculate the survival curves. Factors of prognostic significance in the univariate analysis were further analyzed by the model of multivariate Cox regression. For all tests, $p$-values less than 0.05 were considered significant. All statistical data were analyzed by the Statistical Package for the Social Sciences software (SPSS, IBM, version 19.0). All data are represented as mean \pm SEM.

\section{Results}

\section{Spy I mRNA expression in CRC tissues by $q R T-P C R$ analysis and western blotting}

The mRNA expression levels of Spyl were detected by qRT-PCR analyses of 30 pairs of CRC tissues and their corresponding adjacent tissues. Compared with the transcript levels in adjacent tissues, the transcript levels of Spy1 were significantly higher in CRC tissues $(0.8157 \pm 0.1289$ vs $0.6993 \pm 0.1149,1.95$-fold, $p=0.0002$, with Wilcoxon signedrank nonparametric test) (Figure 1).

The expression of Spy1 protein in the CRC tissues and adjacent tissues was confirmed by western blot analysis. The representative results are shown in Figure 2. There were 27 cases $(90 \%)$ of CRC tissues with higher protein level of Spy1 and two cases $(6.67 \%)$ of CRC tissues with similar expression level of Spy1 protein, compared with the adjacent tissues. There was one case (3.33\%) of CRC tissue with lower protein level of Spy1 than that of adjacent tissue. The results indicated that the expressions of Spyl protein in CRC tissues were significantly higher than those in adjacent tissues.

\section{The location and expression of Spyl protein in CRC tissues by immunohistochemistry}

The immunohistochemistry analyses were performed to determine the protein location and expression of Spy1 in CRC

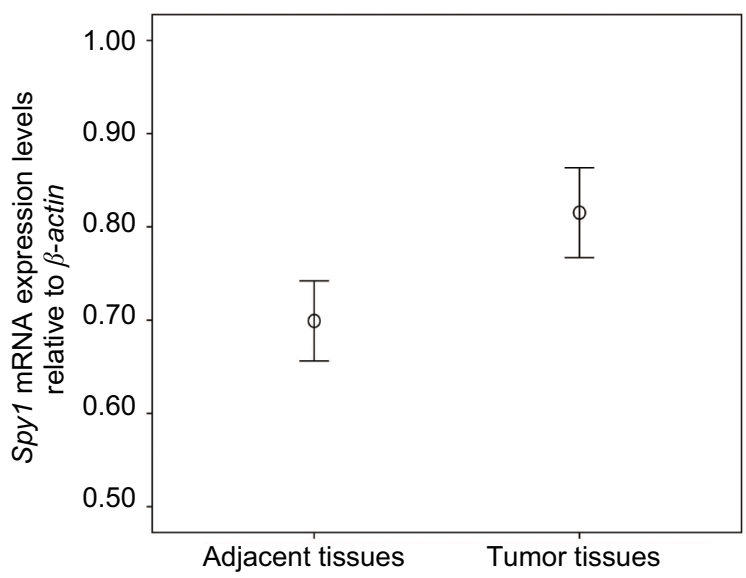

Figure I Quantitative real-time polymerase chain reaction (qRT-PCR) analysis was used to detect SpyI mRNA expression levels in colorectal cancer (CRC) tissues and the adjacent tissues.

Note: The Spyl mRNA levels in CRC tissues were significantly higher than those in the adjacent tissues.

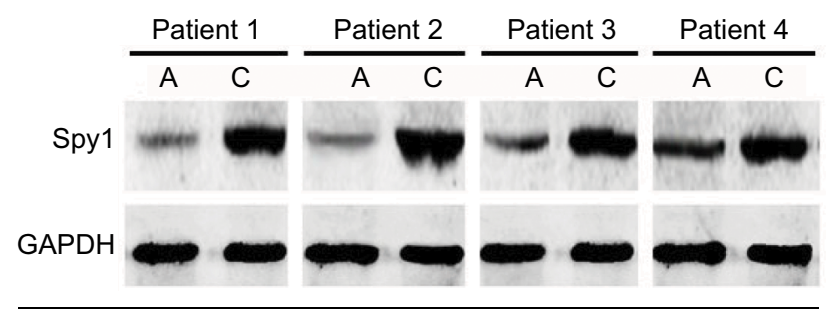

Figure 2 The representative Spyl expression levels in colorectal cancer (CRC) tissues were detected by western blot assay and compared with adjacent tissues. Note: The Spyl levels in CRC tissue were significantly overexpressed compared to those in the adjacent tissues, and GAPDH was used as a loading control. Abbreviations: $\mathrm{A}$, adjacent tissues; $\mathrm{C}$, cancer tissues. 

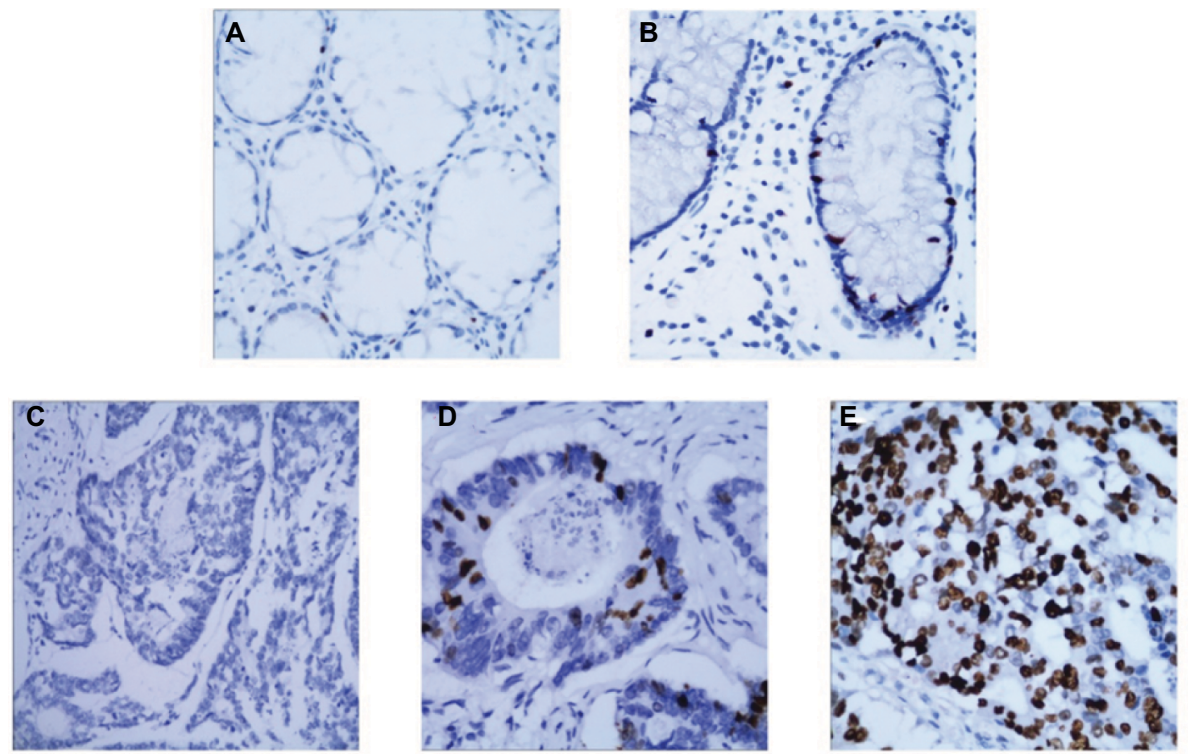

Figure 3 The representative images of the Spyl protein location and expression in colorectal cancer (CRC).

Notes: (A) No immunohistochemistry (IHC) staining of Spyl in the cell nucleus of normal intestinal mucosa. (B) IHC staining of Spyl in the nuclear of normal intestinal mucosa. (C) No IHC staining of Spyl in the nuclear of CRC cells. (D) Moderate IHC staining of Spyl in the nuclear of CRC cells. (E) High IHC staining of Spyl in the nuclear of CRC cells. Original magnification, $\times 400$ in A-E.

tissues and adjacent tissues. As shown in Figure 3, the location of Spy1 expression was mainly detected in the cell nucleus of of CRC tissues. High Spyl expression level was detected in $61.08 \%$ (124/203) of CRC tissues, which was significantly higher $\left(\chi^{2}=19.951, p<0.05\right)$ than that in adjacent tissues $(38.92 \%$ [79/203]).

\section{Correlations between Spyl protein expression and clinicopathological attributes of CRC patients}

The correlations between Spyl protein levels and clinicopathological attributes of CRC patients were investigated (Table 1). Higher expressions of Spyl were significantly associated with T stage $\left(\chi^{2}=7.126, p=0.028\right)$ and TNM stage $\left(\chi^{2}=9.461, p=0.009\right)$. However, Spy1 protein expressions in CRC were not significantly associated with age, sex, tumor size, histological type, location, and differentiation (Table 1).

\section{High Spyl protein expression predicts poor prognosis of CRC patients}

Subsequently, univariate analyses were conducted to evaluate Spyl protein expressions and clinicopathological factors on prognosis of CRC patients. The result showed that the high expression level of Spy1 $(\mathrm{HR}=2.846, p<0.001)$, $\mathrm{T}$ stage $(\mathrm{HR}=1.335, p=0.026)$, and TNM stage $(\mathrm{HR}=1.609, p=0.003)$ were significantly associated with poor overall survival
Table I Association of Spyl expression with clinical characteristics and selected biological markers of CRC

\begin{tabular}{|c|c|c|c|c|c|}
\hline \multirow[t]{2}{*}{ Characteristic } & \multirow[t]{2}{*}{$\mathbf{n}$} & \multicolumn{4}{|c|}{ Spy I expression (\%) } \\
\hline & & High & $\begin{array}{l}\text { Low } \\
\text { or no }\end{array}$ & $\chi^{2}$ & $p$ \\
\hline Age (years) & & & & 1.293 & 0.255 \\
\hline$\leq 60$ & 75 & $42(56.0)$ & $33(44.0)$ & & \\
\hline$>60$ & 128 & $82(64.1)$ & $46(35.9)$ & & \\
\hline Sex & & & & 0.048 & 0.826 \\
\hline Male & 124 & $75(60.5)$ & 49 (39.5) & & \\
\hline Female & 79 & $49(62.0)$ & $30(38.0)$ & & \\
\hline Tumor size $(\mathrm{cm})$ & & & & 0.096 & 0.757 \\
\hline$\leq 5$ & 157 & $95(60.5)$ & $62(39.5)$ & & \\
\hline$>5$ & 46 & $29(63.0)$ & $17(37.0)$ & & \\
\hline $\begin{array}{l}\text { Histological } \\
\text { classification }\end{array}$ & & & & 0.523 & 0.470 \\
\hline Tubular+papillary & 181 & $109(60.2)$ & $72(39.8)$ & & \\
\hline Other & 22 & $15(68.2)$ & $7(31.8)$ & & \\
\hline Location & & & & 4.642 & 0.200 \\
\hline Ascending colon & 66 & $42(63.6)$ & $24(36.4)$ & & \\
\hline Transverse colon & 27 & $18(66.7)$ & $9(33.3)$ & & \\
\hline $\begin{array}{l}\text { Descending } \\
\text { colon+sigmoid colon }\end{array}$ & 60 & $30(50.0)$ & $30(50.0)$ & & \\
\hline Rectum & 50 & $34(68.0)$ & $16(32.0)$ & & \\
\hline Differentiation & & & & 0.284 & 0.594 \\
\hline Well+moderate & 150 & $90(60.0)$ & $60(40.0)$ & & \\
\hline Poor & 53 & $34(64.2)$ & $19(35.8)$ & & \\
\hline T stage & & & & 7.126 & $0.028 *$ \\
\hline $\mathrm{TI}^{\circ}$ & 45 & $23(5 \mathrm{I} .1)$ & $22(48.9)$ & & \\
\hline $\mathrm{T} 2$ & 87 & $49(56.3)$ & $38(43.7)$ & & \\
\hline $\mathrm{T} 3+\mathrm{T} 4$ & 71 & $52(73.2)$ & $19(26.8)$ & & \\
\hline
\end{tabular}

(Continued) 
Table I (Continued)

\begin{tabular}{|c|c|c|c|c|c|}
\hline \multirow[t]{2}{*}{ Characteristic } & \multirow[t]{2}{*}{$\mathbf{n}$} & \multicolumn{4}{|c|}{ Spy I expression (\%) } \\
\hline & & High & $\begin{array}{l}\text { Low } \\
\text { or no }\end{array}$ & $\chi^{2}$ & $p$ \\
\hline $\mathbf{N}$ stage & & & & 5.334 & 0.069 \\
\hline No & 122 & $78(63.9)$ & $44(36.1)$ & & \\
\hline $\mathrm{NI}$ & 56 & $36(64.3)$ & $20(35.7)$ & & \\
\hline N2 & 25 & $10(40.0)$ & $15(60.0)$ & & \\
\hline TNM stage & & & & 9.461 & $0.009 *$ \\
\hline I & 24 & $10(4 \mid .7)$ & $14(58.3)$ & & \\
\hline II & 53 & $27(50.9)$ & $26(49.1)$ & & \\
\hline III+IV & 136 & $87(69.0)$ & $39(31.0)$ & & \\
\hline
\end{tabular}

Note: $* p<0.05$.

Abbreviation: CRC, colorectal cancer.

of CRC patients (Table 2). These prognostic factors were further evaluated by multivariate Cox proportional hazards regression model analysis. With the Kaplan-Meier analysis, high Spy1 expression $(\mathrm{HR}=2.573, p<0.001)$ and TNM stage ( $\mathrm{HR}=1.494, p=0.011$ ) were found to be independent prognostic markers of poor 5-year overall survival (Table 2). CRC patients with high expression of Spy1 protein had significantly shorter overall survival compared with those with low or no Spyl expression (Figure 4). CRC patients with TNM stage III+IV had significantly shorter overall survival compared with those with stage I and stage II (Figure 4).

\section{Survival analysis of target genes}

High expressions of Spy1 confer survival disadvantages to ACC patients (log rank $p=0.0062$, HR [high]=3), COAD patients (log rank $p=0.03$, HR [high]=1.7) and KIRC patients [(log rank $p=2.3 \mathrm{e}-07, \mathrm{HR}[$ high $]=2.3)$ in the GEPIA dataset with TCGA samples (Figure 5).

\section{Discussion}

$\mathrm{CRC}$ is the most malignant disease in developed and developing countries, largely because of its propensity to metastasize. The therapeutic regimens of fluoropyrimidine chemotherapy (parenteral 5-fluorouracil/leucovorin or oral capecitabine) in combination with oxaliplatin (FOLFOX or XELOX) or irinotecan (FOLFIRI) and bevacizumab (Avastin; Genentech, Inc., South San Francisco, CA, USA) have improved overall survival of CRC. ${ }^{22}$ Furthermore, targeted treatments like anti-VEGF, anti VEGFR, or anti-EGFR depending on the all-RAS status ${ }^{23,24}$ and anti-PDL-1 (pembrolizumab) according to the microsatellite instability (MSI) status and PDL-1 expression ${ }^{25,26}$ have been used for clinical trials. However, the therapeutic responses vary individually. Additional genetic targeted therapies for CRC still need exploration. ${ }^{27}$

Tumor cells accumulate alterations that result in constitutive mitogenic signaling and defective responses to anti-mitogenic signals that contribute to unscheduled

Table 2 Univariate and multivariate analysis of prognostic factors in CRC for 5-year overall survival

\begin{tabular}{|c|c|c|c|c|c|c|}
\hline & \multicolumn{3}{|c|}{ Univariate analysis } & \multicolumn{3}{|c|}{ Multivariate analysis } \\
\hline & HR & $p$-value & $95 \% \mathrm{Cl}$ & HR & $p$-value & $95 \% \mathrm{Cl}$ \\
\hline \multicolumn{7}{|l|}{ Expression of Spy I } \\
\hline High vs low or no expression & 2.846 & $<0.00 I^{*}$ & I.828-4.429 & 2.573 & $<0.00 I^{*}$ & $1.647-4.019$ \\
\hline \multicolumn{7}{|l|}{ Age (years) } \\
\hline$\leq 60$ vs $>60$ & 1.031 & 0.879 & $0.696-1.527$ & & & \\
\hline \multicolumn{7}{|l|}{ Sex } \\
\hline Male vs female & 0.874 & $0.50 \mathrm{I}$ & $0.592-1.292$ & & & \\
\hline \multicolumn{7}{|l|}{ Tumor size (cm) } \\
\hline$\leq 5$ vs $>5$ & 1.133 & 0.584 & $0.724-1.772$ & & & \\
\hline \multicolumn{7}{|l|}{ Histological classification } \\
\hline Tubular+papillary vs other & 0.897 & 0.732 & $0.48 \mathrm{I}-1.673$ & & & \\
\hline \multicolumn{7}{|l|}{ Location } \\
\hline Ascending colon vs transverse colon vs & 0.873 & 0.103 & $0.742-1.028$ & & & \\
\hline \multicolumn{7}{|l|}{ descending colon + sigmoid colon } \\
\hline \multicolumn{7}{|l|}{ Differentiation } \\
\hline Well+moderate vs poor & 0.765 & 0.168 & $0.522-1.120$ & & & \\
\hline T stage & & & & 1.266 & 0.075 & $0.977-1.64 \mid$ \\
\hline $\mathrm{TI}$ vs $\mathrm{T} 2$ vs $\mathrm{T} 3+\mathrm{T} 4$ & 1.335 & $0.026 *$ & $1.034-1.723$ & & & \\
\hline \multicolumn{7}{|l|}{ N stage } \\
\hline No vs NI vs N2 & 1.203 & 0.201 & $0.906-1.597$ & & & \\
\hline \multicolumn{7}{|l|}{ TNM stage } \\
\hline I vs II vs III+IV & 1.609 & $0.003^{*}$ & I. $178-2.197$ & 1.494 & $0.011 *$ & $1.096-2.037$ \\
\hline
\end{tabular}

Note: $* p<0.05$.

Abbreviation: $C R C$, colorectal cancer. 

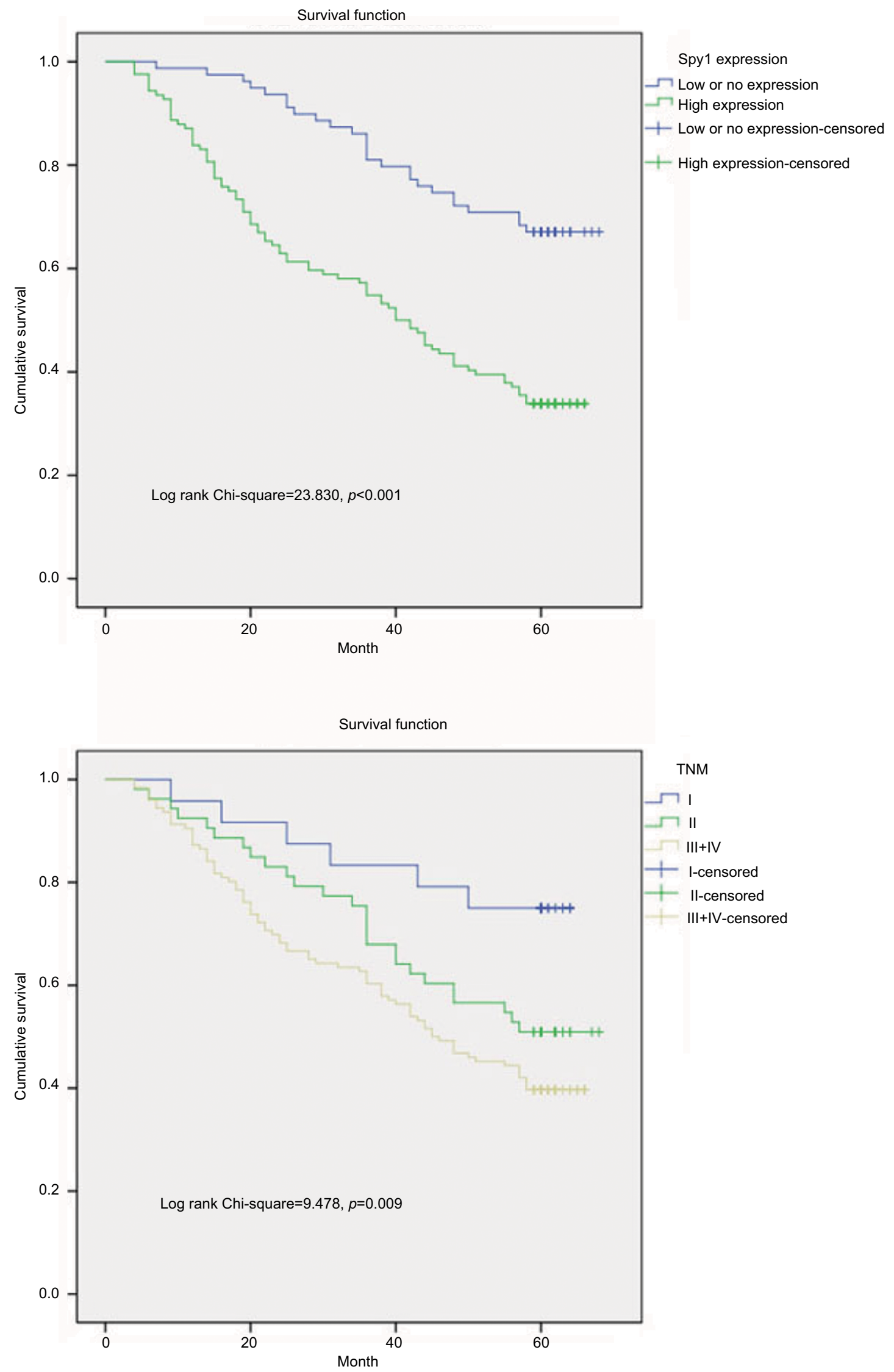

Figure 4 The survival analysis of colorectal cancer (CRC) patients by Kaplan-Meier analysis.

Notes: Overall survival rates in CRC patients with high expression level of Spyl (green line) were statistically lower than those in CRC patients with low or no Spyl expression (blue line). Overall survival rates in CRC patients with high expression levels of TNM stage III+IV (yellow line) were statistically lower than those in CRC patients with TNM stage I (blue line) and II (green line). 

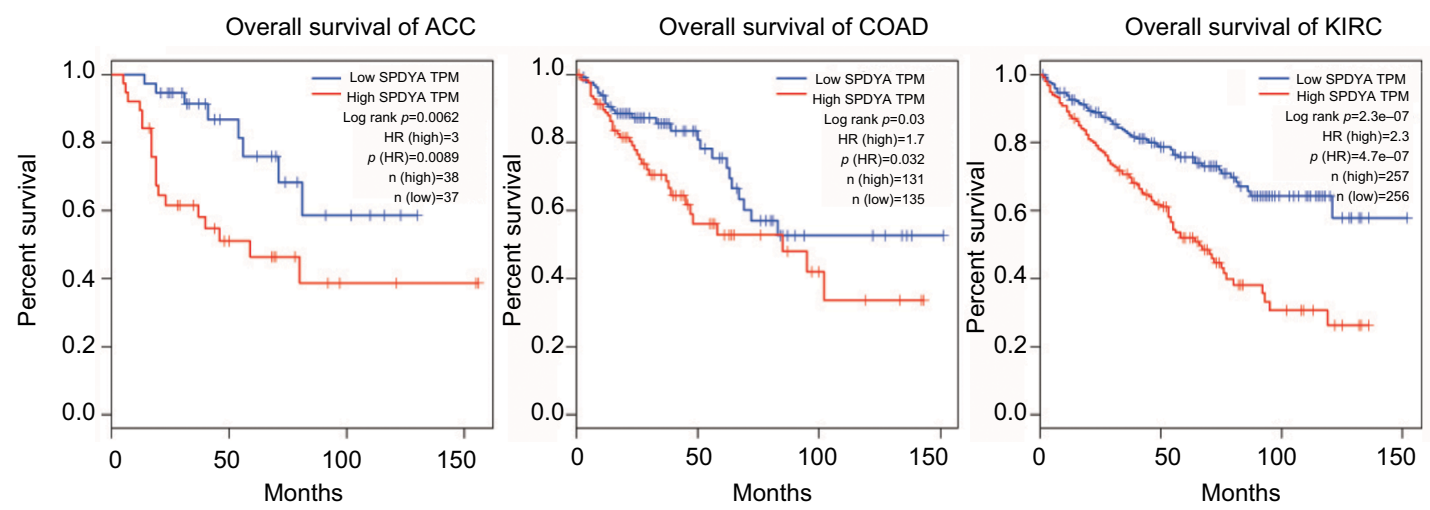

Figure 5 Expression of Spyl in cancers.

Notes: Overall survival rates in adrenocortical carcinoma (ACC), colon adenocarcinoma (COAD) and kidney renal clear cell carcinoma (KIRC) patients with high expression levels of Spy I (red line) were statistically lower than those in patients with low and no Spyl expression (blue line).

Abbreviations: SPADY, Spyl; TPM, transcripts per kilobase of exonmodel per million mapped reads; HR, hazard ratio.

proliferation. These mutations, taken together, result not only in proliferative advantages but also in increased susceptibility to the accumulation of additional genetic alterations that contribute to tumor progression and acquisition of more aggressive phenotypes.

In addition, most tumors acquire genomic instability (GIN) that leads to additional mutations. The acquisition of GIN is a crucial feature in tumor development, and there are at least three distinct pathways in CRC: the CIN, MSI, and $\mathrm{CpG}$ island methylator phenotype pathways. ${ }^{28,29}$ Most cases of CRC arise through the CIN pathway by widespread imbalances in chromosome number (aneuploidy) and loss of heterozygosity due to the defects in chromosomal segregation, telomere stability, and the DNA damage response.

The basic cell cycle defects such as GIN or CIN are mediated, directly or indirectly, by misregulations of CDKs. During the past two decades, a vast body of literature has illustrated the relevance of cell cycle deregulation in human cancer, and targeting the cell cycle in general and CDK in particular presents unique opportunities for drug discovery. ${ }^{30}$

Firstly, isolated in Xenopus, Xenopus-Spy1 could induce rapid meiotic maturation and premature activation of CDKs. ${ }^{15,31}$ Subsequently, Spy1 was found to be expressed in a variety of human tissues, and its overexpression enhances G1-S phase progression, $\mathrm{p} 27^{\mathrm{kip}}$ degradation, ${ }^{12}$ and cellular proliferation by activating CDK2. ${ }^{32,33}$ Spy 1 is also required for cell-cycle re-entry in maturing vertebrate oocytes. ${ }^{34}$ There are multiple isoforms of Spy1 that are now classified into a larger family of proteins, known as the Spy1/RINGO family. Furthermore, abrogation of Spyl expression through the use of siRNA hinders cell proliferation, thus demonstrating that Spy 1 is an essential component of cell proliferation pathways. ${ }^{18}$ These findings open up new possibilities that this gene may be involved in human cell cycle disorders such as oncogenesis. ${ }^{35}$ To date, no study has been performed for Spy1 expression using the group of CRC specimens, and the present study is the first to analyze the Spy1 expression in CRC, with respect to possible associations with clinicopathological data as well as patients' poor prognosis.

In this study, the expression levels of Spy1 in CRC tissues, with adjacent tissues, were detected with the observation that both Spy1 mRNA and protein levels were significantly higher in CRC tissues than those in the adjacent tissues. High Spy1 protein level was associated with poor overall survival for CRC patients, which indicated that Spy1 protein level may be used as an independent clinical marker in predicting unfavorable prognosis.

GEPIA is an interactive web application for gene expression analysis based on 9,736 tumors and 8,587 normal samples from the TCGA and the GTE databases. ${ }^{21}$ Using the GEPIA datasets, we have revealed that Spy1 expression levels are positively correlated with the survival of ACC, COAD, and KIRC cancer patients. Combined with the expression model, we predict that Spy1 plays an important role in cancer progression and may be a candidate biomarker.

Taken together, we analyzed the Spy1 expression in $\mathrm{CRC}$ and demonstrated that Spy1 was involved in CRC development. The findings indicated that Spyl may act as an oncogene during CRC development and it could be identified as a novel prognostic biomarker in CRC clinical treatment. Related studies concerning the potential mechanisms of Spy1 in CRC and other kinds of human cancers are being performed by our research group. 


\section{Acknowledgment}

This work was supported by the Inner Mongolia Science and Technology Research Project (2017ZD04 to Yanfeng Dai and 201502107 and 2017MS08137 to Yuzhen Ma).

\section{Disclosure}

The authors report no conflicts of interest in this work.

\section{References}

1. Siegel R, Desantis C, Jemal A. Colorectal cancer statistics, 2014. $C A$ Cancer J Clin. 2014;64(2):104-117.

2. Day LW, Velayos F. Colorectal cancer screening and surveillance in the elderly: updates and controversies. Gut Liver. 2015;9(2):143-151.

3. Zavoral M, Suchanek S, Majek O, et al. Colorectal cancer screening: 20 years of development and recent progress. World J Gastroenterol. 2014;20(14):3825-3834.

4. Bajenova O, Chaika N, Tolkunova E, et al. Carcinoembryonic antigen promotes colorectal cancer progression by targeting adherens junction complexes. Exp Cell Res. 2014;324(2):115-123.

5. Wang YR, Yan JX, Wang LN. The diagnostic value of serum carcinoembryonic antigen, alpha fetoprotein and carbohydrate antigen 19-9 for colorectal cancer. J Cancer Res Ther. 2014;10 Suppl:307-309.

6. Shibutani M, Maeda K, Nagahara H, et al. Significance of CEA and CA19-9 combination as a prognostic indicator and for recurrence monitoring in patients with stage II colorectal cancer. Anticancer Res. 2014;34(7):3753-3758.

7. Brenner H, Stock C, Hoffmeister M. Effect of screening sigmoidoscopy and screening colonoscopy on colorectal cancer incidence and mortality: systematic review and meta-analysis of randomised controlled trials and observational studies. BMJ. 2014;348:g2467.

8. Byun JY, Yoon SJ, Oh IH, Kim YA, Seo HY, Lee YH. Economic burden of colorectal cancer in Korea. J Prev Med Public Health. 2014;47(2):84-93.

9. Pickhardt PJ, Hassan C, Halligan S, Marmo R. Colorectal cancer: CT colonography and colonoscopy for detection - systematic review and meta-analysis. Radiology. 2011;259(2):393-405.

10. Lim S, Kaldis P. Cdks, cyclins and CKIs: roles beyond cell cycle regulation. Development. 2013;140(15):3079-3093.

11. McAndrew CW, Gastwirt RF, Donoghue DJ. The atypical CDK activator Spy1 regulates the intrinsic DNA damage response and is dependent upon p53 to inhibit apoptosis. Cell Cycle. 2009;8(1):66-75.

12. McAndrew CW, Gastwirt RF, Meyer AN, Porter LA, Donoghue DJ. Spy1 enhances phosphorylation and degradation of the cell cycle inhibitor p27. Cell Cycle. 2007;6(15):1937-1945.

13. Ferraiuolo RM, Tubman J, Sinha I, Hamm C, Porter LA. The cyclin-like protein, SPY1, regulates the ER $\alpha$ and ERK1/2 pathways promoting tamoxifen resistance. Oncotarget. 2017;8(14):23337-23352.

14. Barnes EA, Porter LA, Lenormand JL, Dellinger RW, Donoghue DJ. Human Spy1 promotes survival of mammalian cells following DNA damage. Cancer Res. 2003;63(13):3701-3707.

15. Al Sorkhy M, Ferraiuolo RM, Jalili E, et al. The cyclin-like protein Spy1/RINGO promotes mammary transformation and is elevated in human breast cancer. BMC Cancer. 2012;12:45.

16. Zucchi I, Mento E, Kuznetsov VA, et al. Gene expression profiles of epithelial cells microscopically isolated from a breast-invasive ductal carcinoma and a nodal metastasis. Proc Natl Acad Sci U SA. 2004;101(52): $18147-18152$.
17. Lu S, Liu R, Su M, et al. Spyl participates in the proliferation and apoptosis of epithelial ovarian cancer. J Mol Histol. 2016;47(1):47-57.

18. Ke Q, Ji J, Cheng C, et al. Expression and prognostic role of Spy1 as a novel cell cycle protein in hepatocellular carcinoma. Exp Mol Pathol. 2009;87(3):167-172.

19. Fei M, Hang Q, Hou S, Ruan C. Cell adhesion to fibronectin downregulates the expression of Spy1 and contributes to drug resistance in multiple myeloma cells. Int J Hematol. 2013;98(4):446-455.

20. Patel SH, Kneuertz PJ, Delgado M, et al. Clinically relevant biomarkers to select patients for targeted inhibitor therapy after resection of hepatocellular carcinoma. Ann Surg Oncol. 2011;18(12):3384-3390.

21. Tang Z, Li C, Kang B, Gao G, Li C, Zhang Z. GEPIA: a web server for cancer and normal gene expression profiling and interactive analyses. Nucleic Acids Res. 2017;45(W1):W98-W102.

22. Berlin J, Bendell JC, Hart LL, et al. A randomized phase II trial of vismodegib versus placebo with FOLFOX or FOLFIRI and bevacizumab in patients with previously untreated metastatic colorectal cancer. Clin Cancer Res. 2013;19(1):258-267.

23. Wang JX, Wu HL, Zhu M, Zhou R. Role of anti-epidermal growth factor receptor therapy compared with anti-vascular endothelial growth factor therapy for metastatic colorectal cancer: an update meta-analysis of randomized clinical trials. Pathol Oncol Res. Epub 2018 Jan 30.

24. Khattak MA, Martin H, Davidson A, Phillips M. Role of first-line antiepidermal growth factor receptor therapy compared with anti-vascular endothelial growth factor therapy in advanced colorectal cancer: a meta-analysis of randomized clinical trials. Clin Colorectal Cancer. 2015;14(2):81-90.

25. Sehdev A, Cramer HM, Ibrahim AA, Younger AE, O'Neil BH. Pathological complete response with anti-PD-1 therapy in a patient with microsatellite instable high, BRAF mutant metastatic colon cancer: a case report and review of literature. Discov Med. 2016;21(117):341-347.

26. Toh JWT, de Souza P, Lim SH, et al. The potential value of immunotherapy in colorectal cancers: review of the evidence for programmed death-1 inhibitor therapy. Clin Colorectal Cancer. 2016;15(4): 285-291.

27. Zhang J, Zhou L, Zhao S, Dicker DT, El-Deiry WS. The CDK4/6 inhibitor palbociclib synergizes with irinotecan to promote colorectal cancer cell death under hypoxia. Cell Cycle. 2017;16(12):1193-1200.

28. Pino MS, Chung DC. The chromosomal instability pathway in colon cancer. Gastroenterology. 2010;138(6):2059-2072.

29. Issa JP. Colon cancer: it's CIN or CIMP. Clin Cancer Res. 2008;14(19): 5939-5940.

30. Vermeulen K, Van Bockstaele DR, Berneman ZN. The cell cycle: a review of regulation, deregulation and therapeutic targets in cancer. Cell Prolif. 2003;36(3):131-149.

31. Karaiskou A, Perez LH, Ferby I, Ozon R, Jessus C, Nebreda AR. Differential regulation of Cdc2 and Cdk2 by RINGO and cyclins. J Biol Chem. 2001;276(38):36028-36034.

32. Porter LA, Kong-Beltran M, Donoghue DJ. Spy1 interacts with p27Kip1 to allow G1/S progression. Mol Biol Cell. 2003;14(9):3664-3674.

33. Porter LA, Dellinger RW, Tynan JA, et al. Human Speedy: a novel cell cycle regulator that enhances proliferation through activation of Cdk2. J Cell Biol. 2002;157(3):357-366.

34. Arumugam K, MacNicol MC, Wang Y, et al. Ringo/cyclin-dependent kinase and mitogen-activated protein kinase signaling pathways regulate the activity of the cell fate determinant Musashi to promote cell cycle re-entry in Xenopus oocytes. J Biol Chem. 2012;287(13): 10639-10649.

35. Nebreda AR. CDK activation by non-cyclin proteins. Current Opinion in Cell Biology. 2006;18(2):192-198. 
Cancer Management and Research

\section{Publish your work in this journal}

Cancer Management and Research is an international, peer-reviewed open access journal focusing on cancer research and the optimal use of preventative and integrated treatment interventions to achieve improved outcomes, enhanced survival and quality of life for the cancer patient.

The manuscript management system is completely online and includes

Submit your manuscript here: https://www.dovepress.com/cancer-management-and-research-journal

a very quick and fair peer-review system, which is all easy to use. Visit $\mathrm{http}: / / \mathrm{www}$.dovepress.com/testimonials.php to read real quotes from published authors. 